Discussion Paper No. 865

\title{
TARIFFS VERSUS PRODUCTION SUBSIDIES AS INDUSTRY PROTECTION
}

\author{
Yoshitomo Ogawa \\ Yoshiyasu Ono
}

February 2013

The Institute of Social and Economic Research

Osaka University

6-1 Mihogaoka, Ibaraki, Osaka 567-0047, Japan 


\title{
Tariffs versus Production Subsidies as Industry Protection
}

\author{
Yoshitomo Ogawa* and Yoshiyasu Ono ${ }^{\dagger}$
}

February 2013

\begin{abstract}
This paper provides a welfare comparison of a tariff with a combination of a production subsidy to, and a commodity tax on, an import-competing commodity in a two-country economy. We treat some plausible situations of industry protection, including where the initial tariff is above the optimal tariff, where a certain output level of a tariff-imposed commodity must be maintained, and where there is positive externality of its domestic production. In those cases we explore the optimal combination of the production subsidy and the commodity tax and show it to be superior to the tariff from the welfare viewpoint.
\end{abstract}

Keywords: Commodity Tax, Production Subsidy, Tariff, Industry Protection

JEL Classification: F11, F13, H23

*Faculty of Economics, Kinki University, 3-4-1 Kowakae, Higashiosaka, Osaka 577-8502, JAPAN; E-mail: ogawa@eco.kindai.ac.jp

${ }^{\dagger}$ Institute of Social and Economic Research, Osaka University, 6-1 Mihogaoka, Ibaraki, Osaka 567-0047, JAPAN; E-mail: ono@iser.osaka-u.ac.jp. 


\section{Introduction}

A tariff is a typical policy that is aimed to protect a particular industry from foreign imports. ${ }^{1}$ For example, Japan currently imposes high tariffs on various agricultural products for producer protection, e.g., $1705 \%$ on konjac, $1083 \%$ on pea, $778 \%$ on rice, $593 \%$ on peanut and $482 \%$ on butter. However, it comes under mounting pressure in the regime of the General Agreement on Tariffs and Trade (GATT) and the World Trade Organization (WTO). Recent conclusions of various free trade agreements (FTAs) and economic partnership agreements (EPAs) have also accelerated tariff reductions. An alternative policy of industry protection is a production subsidy. For example, Korea implemented an agriculture compensation system when it concluded an FTA with the US. Production subsidies to agricultural sectors in the US and the European Union (EU) amount to around 20 and 70 billion dollars per year, respectively. Noting the expanding importance of such policy changes, we analyze the welfare effect of a replacement of a protective tariff by a production subsidy with a commodity tax. In particular, we compare the welfare effect of a tariff with that of a combination of a production subsidy and a commodity tax when these policies are carried out for the purpose of industry production, and explore the optimal protection policy. ${ }^{2}$

It is well known that a tariff attains higher welfare than a production subsidy when the country has monopoly power in trade (Bhagwati, 1971). However, if a certain degree of industry protection is required, the superiority of a tariff over a production subsidy may be ambiguous. This paper presents a welfare comparison between a tariff and a combination of a production subsidy and a commodity tax in such likely cases as where in an import-competing sector a very high protective tariff is imposed, a certain production level must be maintained, or domestic production of the sector yields some positive externality.

The literature on the optimal tariff is substantial (see, for example, Kaldor, 1940; Graaff, 1949-50; Johnson, 1951-1952; Kemp, 1967; Kennan and Riezman, 1988; Bond, 1990; Lahiri and Ono, 1999; Syropoulos, 2002). However, all of them lack the viewpoint of industry protection. Bhagwati and Ramaswami (1963) and Bhagwati, Ramaswami and Srinivasan (1969) assume general domestic distortions and point out the possibility that commodity and production tax-cum-subsidies increase welfare but do not explicitly discuss their optimal levels. We fill this void and analyze the optimal combination of the production subsidy to, and the commodity tax on, the import-competing sector when the sector has to be protected.

After confirming that a tariff is equivalent to a combination of a production

\footnotetext{
${ }^{1}$ Even now, a tariff is a primary source of government revenue in many developing countries.

${ }^{2}$ Corden (1957) intuitively discussed a production subsidy and a commodity tax as protection policy using a graphical analysis.
} 
subsidy and a commodity tax with the same magnitude as the tariff, we first explore the optimal commodity tax and the optimal production subsidy when they can take different magnitudes. We then examine the welfare effect of replacing the tariff by the combination of the production subsidy and the commodity tax that realizes the same degree of protection. This conversion is found to make the home country better off when the preimposed tariff is higher than the optimal tariff. It may apply to the case of the Japanese rice protection because the $778 \%$ tariff must exceed the optimal rate. Furthermore, we extend the analysis to such cases as where the commodity tax and the production subsidy are chosen so that the tariff-protected industry maintains a certain level of production and where there is production externality, and show the same property to hold.

\section{The Model}

We consider a standard $2 \times 2 \times 2$ general equilibrium competitive model. The home country exports commodity 1 and imports commodity 2 . There are two production factors, labor $L$ and capital $K$, which are fixed in supply and internationally immobile. The home country imposes a commodity tax $(t)$ and a production subsidy $(s)$ on commodity 2 , while the foreign country imposes neither tariffs nor tax-cum-subsidies.

The production function of sector $i(i=1,2)$ in the home country is

$$
y_{i}=f_{i}\left(k_{i}\right) L_{i}, f_{i}^{\prime}>0 \text { and } f_{i}^{\prime \prime}<0, \quad i=1,2,
$$

where $y_{i}$ is output of commodity $i, L_{i}$ and $K_{i}$ are respectively labor and capital inputs in sector $i$, and $k_{i} \equiv K_{i} / L_{i}$. The home firms' optimization behavior leads to

$$
\begin{aligned}
f_{1}^{\prime}\left(k_{1}\right) & =(s+p) f_{2}^{\prime}\left(k_{2}\right)=r \\
f_{1}\left(k_{1}\right)-f_{1}^{\prime}\left(k_{1}\right) k_{1} & =(s+p)\left[f_{2}\left(k_{2}\right)-f_{2}^{\prime}\left(k_{2}\right) k_{2}\right]=w
\end{aligned}
$$

where $p$ is the world price of commodity $2, r$ is the capital rent, $w$ is the wage rate and commodity 1 is taken as numeraire. From (2) we derive

$$
r=r(s+p), \quad w=w(s+p), k_{i}=k_{i}(s+p), \quad i=1,2 .
$$

The factor market equilibrium conditions in the home country are

$$
L_{1}+L_{2}=\bar{L} \text { and } k_{1} L_{1}+k_{2} L_{2}=\bar{K}
$$

where $\bar{L}$ and $\bar{K}$ are the home endowments of the two factors respectively. Equations (1), (3) and (4) give the two sectors' labor demand and commodity supply:

$$
L_{i}=L_{i}(s+p), \quad y_{i}=y_{i}(s+p), \quad \text { for } i=1,2 .
$$


A representative consumer in the home country has a well-behaved utility function $u\left(x_{1}, x_{2}\right)$ where $x_{i}$ is demand for commodity $i$. Both commodities are assumed to be normal and hence the home demand functions

$$
x_{i}=D_{i}(t+p, Y), \quad i=1,2,
$$

satisfy

$$
D_{i Y}\left(\equiv \partial D_{i} / \partial Y\right)>0 \text { for } i=1,2,
$$

where

$$
\begin{aligned}
Y & \equiv y_{1}+(s+p) y_{2}-T \\
T & \equiv s y_{2}-t x_{2}
\end{aligned}
$$

Similarly, the foreign supply, demand and excess demand functions of commodity $i(=1,2)$ are respectively

$$
\begin{aligned}
y_{i}^{*} & =y_{i}^{*}(p), \\
x_{i}^{*} & =x_{i}^{*}(p)=D_{i}^{*}\left(p, Y^{*}\right) \text { where } Y^{*} \equiv y_{1}^{*}(p)+p y_{2}^{*}(p), \\
z_{i}^{*} & =z_{i}^{*}(p)=x_{i}^{*}(p)-y_{i}^{*}(p) .
\end{aligned}
$$

The international market-clearing condition for commodity 2 is

$$
D_{2}(t+p, Y)+D_{2}^{*}\left(p, Y^{*}\right)-y_{2}(s+p)-y_{2}^{*}(p)=0 .
$$

Note that with Walras' law the market-clearing condition for commodity 1 necessarily holds if all the other markets are in equilibrium.

From (1)-(9) we obtain

$$
\begin{gathered}
d y_{2}=y_{2}^{\prime} d(s+p), \\
\left(1-t D_{2 Y}\right) d x_{2}=D_{2 p} d(p+t)+D_{2 Y} \cdot\left[\left(y_{1}^{\prime}+p y_{2}^{\prime}\right) d(s+p)+y_{2} d p+x_{2} d t\right] \\
\Omega d p=-\left(\frac{D_{2 p}}{1-t D_{2 Y}}+\frac{D_{2 Y}}{1-t D_{2 Y}} x_{2}\right) d t+\left(\frac{s D_{2 Y}}{1-t D_{2 Y}}+1\right) y_{2}^{\prime} d s
\end{gathered}
$$

where $D_{2 p} \equiv \partial D_{2} / \partial(p+t)$ and $\Omega$ satisfies.

$$
\begin{aligned}
\Omega & \equiv \frac{D_{2 p}}{1-t D_{2 Y}}+\frac{D_{2 Y}}{1-t D_{2 Y}}\left(y_{2}-s y_{2}^{\prime}\right)+z_{2}^{* \prime}-y_{2}^{\prime}<0, \\
z_{2}^{* \prime} & =D_{2 p}^{*}+D_{2 Y^{*}}^{*} y_{2}^{*}-y_{2}^{* \prime}<0 \\
y_{2}^{\prime} & >0 \\
y_{2}^{* \prime} & >0 .
\end{aligned}
$$

The negativity of $\Omega$ implies the stability condition of the market of commodity 2 , whereas the positivity of $y_{2}^{\prime}$ and that of $y_{2}^{* \prime}$ represent positively-inclined home 
and foreign supply functions of commodity $2 .^{3} z_{2}^{* \prime}$ is naturally assumed to be negative since it represents the own-price effect of $z_{2}^{*}$, the foreign excess demand for commodity 2. Since the foreign country exports commodity 2, from (8) and (9) we find

$$
z_{2}^{*}=x_{2}^{*}-y_{2}^{*}=-\left(x_{2}-y_{2}\right)<0 .
$$

The optimal household behavior yields

$$
\frac{u_{2}}{u_{1}}=t+p
$$

where $u_{i} \equiv \partial u\left(x_{1}, x_{2}\right) / \partial x_{i}$. From (1), (2) and (4), the optimal firm behavior gives

$$
d y_{1}+(s+p) d y_{2}=0
$$

Total differentiation of the balance of payment equation provides

$$
d x_{1}+p d x_{2}+x_{2} d p=d y_{1}+p d y_{2}+y_{2} d p .
$$

Using these three equations and the total differentiation of $u\left(x_{1}, x_{2}\right)$ we find

$$
\frac{d u}{u_{1}}=-\left(x_{2}-y_{2}\right) d p+t d x_{2}-s d y_{2}
$$

Substituting $d p, d x_{2}$ and $d y_{2}$ given in (10) into (16) leads to

$$
\frac{\left(1-t D_{2 Y}\right)}{u_{1}} d u=(t-\Lambda) h_{2} d t+\left[\left(s D_{2 Y}+1-t D_{2 Y}\right) \Lambda-s\right] y_{2}^{\prime} d s
$$

where

$$
\begin{gathered}
h_{2} \equiv D_{2 p}+D_{2 Y} x_{2}<0, \\
\Lambda \equiv \frac{-\left(x_{2}-y_{2}\right)+t h_{2}-s y_{2}^{\prime}}{\left(1-t D_{2 Y}\right) \Omega} .
\end{gathered}
$$

Note that $h_{2}$ in (18), which is the Hicksian own-price effect, is naturally assumed to be negative. By partially differentiating with respect to $Y$ the home budget constraint:

$$
Y=D_{1}(t+p, Y)+(t+p) D_{2}(t+p, Y),
$$

and using (7), we find

$$
1-t D_{2 Y}=D_{1 Y}+p D_{2 Y}>0 .
$$

${ }^{3}>$ From (1), (3) and (5), $y_{2}^{\prime}$ obtains as a function of $k_{2}^{\prime}$ and $L_{2}^{\prime}$. Totally differentiating (2) yields $k_{1}^{\prime}$ and $k_{2}^{\prime}$. Substituting them into the total differentiation of (4) gives $L_{2}^{\prime}$. By applying $k_{2}^{\prime}$ and $L_{2}^{\prime}$ thus obtained to the expression of $y_{2}^{\prime}$ and using (2) we eventually find $y_{2}^{\prime}$ to be positive. The positivity of $y_{2}^{* \prime}>0$ analogously obtains. 


\section{Optimal Commodity Tax and Production Sub- sidy}

Having set up the model we now turn to analyze the properties of the optimal commodity tax and the production subsidy.

From (17) and (19) we obtain the effects of changes in $s$ and $t$ on utility $u$. Applying the sign properties of (11), (12), (18) and (20) to the results yields

$$
\begin{aligned}
\left.\left(\frac{1}{u_{1}}\right) \frac{d u}{d t}\right|_{t=0, s=\text { const. }} & =\left(\frac{1}{\Omega}\right)\left[\left(x_{2}-y_{2}\right)+s y_{2}^{\prime}\right] h_{2}>0 \\
\left.\left(\frac{1}{u_{1}}\right) \frac{d u}{d s}\right|_{s=0, t=\text { const. }} & =\left[\frac{1}{\left(1-t D_{2 Y}\right) \Omega}\right]\left[-\left(x_{2}-y_{2}\right)+t h_{2}\right] y_{2}^{\prime}>0 .
\end{aligned}
$$

Therefore, we obtain the following proposition:

Proposition 1. (i) Offering a low production subsidy to the import-competing sector improves welfare when a non-negative commodity tax is imposed on the sector, and (ii) imposing a low commodity tax on the sector improves welfare when a non-negative production subsidy is offered to the sector.

This proposition shows that offering a low production subsidy to the importcompeting sector still improves welfare even if a commodity tax above the optimal tariff level has already been imposed on the sector, and that imposing a low commodity tax on the sector still improves welfare even if a production subsidy above the optimal tariff level has already been offered to the sector. Thus, the optimal tariff implication (namely, the positive effect of an improvement in the terms of trade through an import restriction) still holds for a low production subsidy irrespective of the level of the predetermined commodity tax, and for a low commodity tax irrespective of the level of the predetermined production subsidy.

Let us next turn to the optimal combination of the commodity tax and the production subsidy. From (17) they satisfy

$$
t=\Lambda, \quad s=\left(1-t D_{2 Y}\right) \Lambda /\left(1-D_{2 Y} \Lambda\right),
$$

and hence using (11), (12) and (19) we obtain

$$
t^{\mathrm{opt}}=s^{\mathrm{opt}}=\Phi, \quad \Phi \equiv z_{2}^{*} / z_{2}^{* \prime}>0,
$$

where $z_{2}^{* \prime}$ and $z_{2}^{*}$ are respectively given by (11) and (12) and $\Phi$ is equivalent to the optimal tariff. ${ }^{4}$ This property is formally restated as follows:

\footnotetext{
${ }^{4}$ Bhagwati (1971) intuitively discusses this property but does not give a formal proof.
} 
Proposition 2. The optimal combination of the commodity tax and the production subsidy is equivalent to the optimal tariff.

Noting that a tariff is equivalent to the combination of production subsidy $s$ and commodity tax $t$ that have the same magnitude as the tariff, we next consider the case where the tariff is separated into the production subsidy and the commodity tax and only the commodity tax is revised while the production subsidy is maintained in order for the import-competing sector to be protected. For example, Japan currently imposes a $778 \%$ tariff rate on imported rice and most likely the tariff rate exceeds the optimal tariff level. Replacing the tariff by the production subsidy is often discussed and in fact the Japanese government has adopted an individual income support system in the agriculture sector. In the following we will show that the separation benefits the country.

Suppose that initially

$$
t=s .
$$

Then, $\Omega$ and $z_{2}^{* \prime}$ in (11) and $\Lambda$ in (19) satisfy

$$
t-\Lambda=(t-\Phi)\left(\frac{z_{2}^{* \prime}}{\Omega}\right),
$$

and hence (17) reduces to

$$
\frac{\left(1-t D_{2 Y}\right)}{u_{1}} d u=(t-\Phi)\left(\frac{z_{2}^{* \prime}}{\Omega}\right)\left(h_{2} d t-y_{2}^{\prime} d s\right) .
$$

From (11), (18), (20), (22) and (24), if $s$ is fixed at a higher level than $\Phi$,

$$
\left.\frac{d u}{d t}\right|_{t=s(>\Phi)}<0 .
$$

Next, when $t$ decreases from $s$ and reaches $\Phi$, using (11) and (19) we obtain

$$
t-\Lambda=(s-\Phi)\left(\frac{y_{2}^{\prime}}{\Omega}\right) .
$$

Substituting this into $t-\Lambda$ in (17) where $s(>\Phi)$ is kept constant yields

$$
\frac{\left(1-t D_{2 Y}\right)}{u_{1}} d u=(s-\Phi)\left(\frac{h_{2} y_{2}^{\prime}}{\Omega}\right) d t .
$$

From (10), (11) and (20), the above expression shows

$$
\left.\frac{d u}{d t}\right|_{t=\Phi}>0
$$

(25) and (28) imply the following proposition. 
Proposition 3. Suppose that a tariff higher than the optimal tariff is initially imposed. If the tariff is separated into a production subsidy and a commodity tax and the production subsidy must take the same level as the tariff, the optimal commodity tax is between the initial level and the optimal tariff level.

\section{Production Support and Environmental Preser- vation}

\subsection{Production Support Policy}

This section considers the case where the tariff is replaced by the production subsidy with the commodity tax adjusted so that production of commodity 2 is kept constant. The Japanese individual income support for farmers is indeed distributed according to the past crop average. It should be noted that a production-keeping policy is equivalent to a price-keeping policy in the present setting. The US Counter-Cyclical Payment (CCP), which compensates the difference between the market price and the target price, may be an example of the price-keeping policy.

Let us start the analysis from the situation of (22) and obtain the welfare effect of the above-mentioned policy. If $y_{2}$ is fixed and hence $d y_{2}=0$, from (5) we obtain

$$
0=d s+d p .
$$

Applying this property and (18) to (10) leads to

$$
d s=\theta d t \quad \text { where } \theta \equiv \frac{h_{2}}{\left(1-t D_{2 Y}\right) \Omega+y_{2}^{\prime}} .
$$

From (11) and (22), $\theta$ is rewritten as

$$
\theta=\frac{h_{2}}{h_{2}-D_{2 Y} \cdot\left(x_{2}-y_{2}\right)+\left(1-t D_{2 Y}\right) z_{2}^{* \prime}},
$$

and therefore using (7), the second property of (11), (12), (18) and (20), we find

$$
0<\theta<1 \text {. }
$$

From the second property of (11), (24) and (30), a small change in the commodity tax with the production subsidy following (29) yields

$$
\left.\left(\frac{1}{u_{1}}\right) \frac{d u}{d t}\right|_{y_{2}=\text { const. }}=(t-\Phi) z_{2}^{* \prime} \theta<0 .
$$

This property implies the following: 
Proposition 4. Suppose that initially $s=t>\Phi$. Then, a reduction in the commodity tax $t$ accompanied by a reduction in the production subsidy $s$ that keeps production of commodity 2 constant improves welfare.

Intuitively, a decrease in the commodity tax stimulates demand for commodity 2 , which increases its home producer price. Thus, in order to keep the home production of commodity 2 constant the production subsidy must also be reduced. (11), (20), (22) and (24) imply that when $t$ is kept constant, $d u / d s$ satisfies

$$
\left.\frac{d u}{d s}\right|_{s=t(>\Phi)}<0,
$$

i.e., a reduction in the production subsidy increases home welfare. (25) shows that a reduction in the commodity tax also increases home welfare. Therefore, the decrease in the commodity tax and the subsequent decrease in the production subsidy, mentioned in the proposition, makes the home country better off.

Moreover, from (29) and (30), the subsequent reduction in $s$ that keeps $y_{2}$ constant is smaller than the initial reduction in $t$. Therefore, the beneficial tax reform is indeed a separation of the tariff to the commodity tax and the production subsidy.

\subsection{Environmental Preservation}

This section considers the case with positive production externality, such as environmental preservation owing to agricultural production. The WTO agreement on agriculture allows member countries to give a subsidy to agricultural sectors for environmental preservation or maintenance of areas under cultivation. It is paid according to the past production level and hence is indeed a production subsidy. In this section, we examine how an externality affects the optimal commodity tax and the optimal production subsidy. ${ }^{5}$

To do so, we modify the utility function as

$$
u\left(x_{1}, x_{2}\right)+\beta y_{2},
$$

where $\beta(>0)$ shows such externality. For given $\beta$, totally differentiating the utility and applying (13), (14) and (15) to the result yields

$$
\frac{d u}{u_{1}}=d x_{1}+(t+p) d x_{2}+\beta d y_{2}=-\left(x_{2}-y_{2}\right) d p+t d x_{2}-(s-\beta) d y_{2} .
$$

\footnotetext{
${ }^{5}$ Markusen (1975, p.19) analyzes the optimal combination of a tariff, instead of a commodity tax, and a production tax in the presence of externality.
} 
Using (10) and (11), we rewrite it as follows:

$$
\begin{aligned}
\frac{\left(1-t D_{2 Y}\right)}{u_{1}} d u=(t & \left.-\Lambda-\frac{\beta y_{2}^{\prime}}{\Omega}\right) h_{2} d t+\left[\left(s D_{2 Y}+1-t D_{2 Y}\right) \Lambda-s\right. \\
& \left.+\left\{D_{2 p}+D_{2 Y} y_{2}+\left(1-t D_{2 Y}\right) z_{2}^{* \prime}\right\}\left(\frac{\beta}{\Omega}\right)\right] y_{2}^{\prime} d s .
\end{aligned}
$$

Therefore, the optimal tax and the optimal subsidy must satisfy

$$
\begin{gathered}
t^{o p t}-\Lambda-\frac{\beta y_{2}^{\prime}}{\Omega}=0 \\
\left(s^{o p t} D_{2 Y}+1-t^{o p t} D_{2 Y}\right) \Lambda-s^{o p t}+\left[D_{2 p}+D_{2 Y} y_{2}+\left(1-t^{o p t} D_{2 Y}\right) z_{2}^{* \prime}\right]\left(\frac{\beta}{\Omega}\right)=0 .
\end{gathered}
$$

From these two equations in which $\Omega$ and $\Lambda$ are respectively given by (11) and (19), we obtain the optimal tax and subsidy mentioned below.

Proposition 5. In the presence of production externality $\beta$ the optimal tax and the optimal subsidy are

$$
t^{o p t}=\Phi, \quad s^{o p t}=\Phi+\beta,
$$

where $\Phi \equiv z_{2}^{*}(p) / z_{2}^{* \prime}(p)$

By comparing the equations in proposition 5 with (21) we find that without externality $\beta$ the implication of proposition 5 is the same as that of proposition 2 , that is, the optimal combination of the production subsidy and the commodity tax is equivalent to the optimal tariff $\Phi$. In the presence of externality $\beta$, however, the production subsidy must be higher than the commodity tax by the magnitude of the externality.

The existence of the externality strengthens the benefit of separating the tariff into the production subsidy and the commodity tax and lowering the commodity tax only. In fact, from (23), (26) and (31) we obtain

$$
\begin{aligned}
& \left.\frac{\left(1-t D_{2 Y}\right)}{u_{1}} \frac{d u}{d t}\right|_{t=s}=(t-\Phi)\left(\frac{z_{2}^{* \prime} h_{2}}{\Omega}\right)-\beta\left(\frac{h_{2} y_{2}^{\prime}}{\Omega}\right), \\
& \left.\frac{\left(1-t D_{2 Y}\right)}{u_{1}} \frac{d u}{d t}\right|_{t=\Phi}=[s-(\Phi+\beta)]\left(\frac{h_{2} y_{2}^{\prime}}{\Omega}\right) .
\end{aligned}
$$

Obviously, $-\beta h_{2} y_{2}^{\prime} / \Omega$, which is negative from (11) and (18), represents the externality effect, which enhances the benefit of a reduction in the commodity tax, shown in proposition 3. By comparing them with (24) and (27) respectively, we find that (32) is negative and that (33) is positive. Thus, if the production subsidy is higher than the first-best optimal level $\Phi+\beta$, the optimal commodity tax is between $s$ and $\Phi$-i.e., basically the same implication as proposition 3 holds. 
Proposition 6. If a country must offer a higher production subsidy than the first-best optimal level, the optimal commodity tax is between the level of the production subsidy and its own first-best optimal level.

Next, we examine the effect of a change in $\beta$ on $s^{\text {opt }}$ and $t^{\text {opt }}$. Noting that $\Phi$ depends only on $p$, from the equations in proposition 5 we find

$$
d t^{o p t}=\Phi^{\prime} d p, \quad d s^{o p t}=d \beta+\Phi^{\prime} d p,
$$

where $\Phi^{\prime}=d \Phi / d p$. Applying the property that $s^{o p t}-t^{\text {opt }}=\beta$, stated in proposition 5 , and the above equations to the last equation of (10) yields

$$
\frac{d t^{o p t}}{d \beta}=\frac{\left(\beta D_{2 Y}+1\right) y_{2}^{\prime} \Phi^{\prime}}{\left(1-t^{\text {opt }} D_{2 Y}\right) \Omega+h_{2} \Phi^{\prime}-\left(\beta D_{2 Y}+1\right) y_{2}^{\prime} \Phi^{\prime}} .
$$

From (11), (18), (20), (34) and the above equation, we obtain

$$
-1<\frac{d t^{o p t}}{d \beta}<0 \text { and } 0<\frac{d s^{o p t}}{d \beta}<1 \text { if } \Phi^{\prime}>0 .
$$

Therefore, if $\Phi^{\prime}>0$, as externality $\beta$ is larger, the optimal commodity tax decreases and the optimal production subsidy increases but the magnitudes of the changes are less than the magnitude of the increase in the externality. Moreover, using (21) we find $\Phi^{\prime}$ to satisfy

$$
\Phi^{\prime}=\frac{\left(z_{2}^{* \prime}\right)^{2}-z_{2}^{*} z_{2}^{* \prime \prime}}{\left(z_{2}^{* \prime}\right)^{2}}>0 \text { if }\left(z_{2}^{* \prime}\right)^{2}>z_{2}^{*} z_{2}^{* \prime \prime} .
$$

Since $z_{2}^{*}\left(=x_{2}^{*}-y_{2}^{*}\right)<0$ as shown in (12), the above condition is valid if $z_{2}^{* \prime \prime} \geq 0$, that is, if the foreign excess demand for commodity 2 is non-convex with respect to the price.

The above results are summarized as follows.

Proposition 7. Suppose that $\left(z_{2}^{* \prime}\right)^{2}>z_{2}^{*} z_{2}^{* \prime \prime}$, which holds when the foreign excess demand of commodity 2 is non-convex, and that production of commodity 2 yields positive externality, e.g. environmental preservation. If the externality expands, the optimal production subsidy increases and the magnitude of the increase is less than the expansion of the externality. The optimal commodity tax decreases and the magnitude of the decrease is less than the expansion of the externality.

\section{Conclusion}

This paper examines the welfare effects of separating a protective tariff to a production subsidy to, and a commodity tax on, the protected sector in various 
plausible situations, including the cases where (i) the initial tariff is set above the optimal tariff, (ii) domestic production of the protected commodity must be maintained, and (iii) there is positive externality of the sector's domestic production. We show that separating a protective tariff to a commodity tax and a production subsidy and lowering only the commodity tax makes the home country better off in these situations. Without any distortion of such, however, the optimal combination of the subsidy and the tax is equivalent to the optimal tariff.

In Japan there are recently lively debates on the forms of protection policies for several agricultural products on which very high protective tariffs are imposed. EU and Switzerland have increased the amount of direct payment to agricultural sectors while reducing tariffs (or market price supports) on agricultural products (OECD, 2010). The present results imply that a shift from a tariff to the combination of a production subsidy and a commodity tax benefits the country if the sector must be protected.

\section{References}

Bhagwati, J. N., Ramaswami, V. K., 1963. Domestic distortions, tariffs and the theory of optimum subsidy. Journal of Political Economy 71, 44-50.

Bhagwati, J. N., Ramaswami, V. K., Srinivasan, T. N., 1969. Domestic distortions, tariffs and the theory of optimum subsidy: some further results. Journal of Political Economy 77, 1005-10.

Bhagwati, J. N., 1971. The generalized theory of distortions and welfare, in Trade, Balance of Payments and Growth, edited by J.N. Bhagwati et al., Amsterdam, North-Holland.

Bond, E. W., 1990. The optimal tariff structure in higher dimensions. International Economic Review 31, 103-116.

Corden, W. M., 1957. Tariffs, subsidies and the terms of trade. Economica 95, $235-242$.

Graaff, J., 1949-50. On optimal tariff structures. Review of Economic Studies $17,47-59$.

Johnson, H. G., 1951-52. Optimum welfare and maximum revenue tariffs. Review of Economic Studies 19, 28-35.

Kaldor, N., 1940. A note on tariffs and terms of trade. Economica 7, 377-380. 
Kemp, M. C., 1967. Notes on the theory of optimal tariffs. Economic Record 43, 395-403.

Kennan, J., Riezman, R., 1988. Do big countries win tariff wars? International Economic Review 29, 81-85.

Lahiri, S., Ono, Y., 1999. Optimal Tariffs in the Presence of Middleman. Canadian Journal of Economics 32, 55-70.

Markusen, J. R., 1975. International externalities and optimal tax structures. Journal of International Economics 5, 15-29.

OECD, 2010. Agricultural Policies in OECD Countries 2010: At a Glance. Paris, OECD Publishing.

Syropoulos, C., 2002. Optimal tariffs and retaliation revisited: how country size matters. Review of Economic Studies 69, 707-727. 